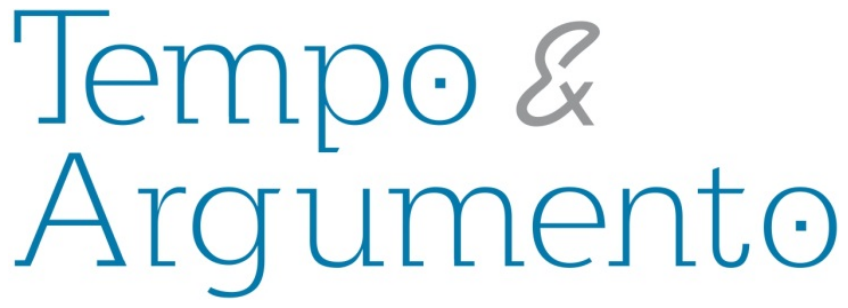

\title{
O ensino de temas controversos na escola francesa: os novos fundamentos da história escolar na França?
}

\section{Resumo}

Este artigo lança um olhar sobre as funções sociais da história na escola, na França, para descrever as principais finalidades da história, regularmente enunciadas desde a segunda metade do século XIX. O autor relembra a problemática do ensino das questões delicadas da história, que emerge nos debates escolares, públicos e políticos na Franca. Acompanhando nisto os debates sobre as questões de memórias, as atividades de sala de aula estão sujeitas à interrogação de uma sociedade inteiramente convidada a perscrutar o interior da escola e de seus conteúdos de ensino da história, a fim de ver nela ocultações, faltas ou amnésias nacionais. Em seguida, o autor analisa a virada memorial que data dos anos 1980 que se vê nas prescrições escolares, para falar do problema do lugar que ocupam em sala de aula os traumas da história nacional e também da maneira pela qual a história é convocada a falar sobre a vitimização, para falar sobre o horror da história, como, por exemplo, a questão do Holocausto ou da colonização e a reação dos alunos em face de tais temas delicados. De todo modo, ensinar os dramas do passado ou os assuntos controvertidos da história nacional marca uma ruptura com uma tradição escolar, mas também acadêmica francesa: enquanto a história ensinada colocava em primeiro plano os ancestrais aureolados de glória e de sentimentos nacionais ou cristãos, o retorno forçado no curso dos anos 2000 dos debates sobre a história da Franca e as implicações de memória participou da dessacralização definitiva da Nação, que saiu progressivamente de uma história imóvel, chauvinista, balizada pelas figuras heroicas cujo destino se confundia como da nação.

\section{Benoit Falaize}

Licenciado em Sociologia Política (DEA

Paris-I Sorbonne. Atualmente é professor de história e doutorando na

Universidade de Cergy Pontoise.

b.falaize@voila.fr

Tradução

Fabrício Coelho

Mestre em Estudos da Tradução pela

Universidade Federal de Santa Catarina fabricioconiglio@gmail.com

Palavras-chave: Ensino de história; História recente da França; Holocausto; Colonização; Memórias.

\section{Para citar este artigo :}

FALAIZE, Benoit. O ensino de temas controversos na escola francesa: os novos fundamentos da história escolar na França? Revista Tempo e Argumento, Florianópolis, v. 6, n. 11, p. 224-253, jan./abr. 2014. Título original: L'enseignement des sujets controversés dans l'école française : les nouveaux fondements de l'histoire scolaire en France? Traduzido por Fabrício Coelho. 


\title{
Controversial subjects teaching in French schools: new grounds for school history in France?
}

\begin{abstract}
This article takes a look at the social functions of history in school, in France, to describe the main purposes of history teaching, regularly stated since the second half of the nineteenth century. The author recalls the question of teaching sensitive issues of history, which emerges in public and political debates about schooling. Accompanying in that the debates around questions of memory, classroom activities are subject to the interrogation of an entire society, invited to examine the interior of school and its content of history teaching, ready to find concealments, insufficiencies, or national amnesia. Then the author analyzes the memorial turn that dates from the 1980s, which is seen in school requirements, to discuss the problem of the place that have in classroom the traumas of national history, how history is called to talk about the victimization and the horrors of history, as, for example, the issue of the Holocaust or colonization, and the reaction of students faced with such sensitive issues. Teaching the dramas of the past or controversial topics of national history can be considered a disruption with a school tradition, but also with an academic tradition in French : while the history taught emphasized the ancestors crowned with glory and national or Christian sentiments, the resurgence in the 2000s of the debates around history and issues of memory in France promoted the final desacralization of the Nation, which went away gradually from a chauvinistic, motionless history, marked by heroic figures whose fate mingled with that of the nation.
\end{abstract}

Keywords: History teaching; Recent history of France; Holocaust; Colonization. Memories. 
Se existe na França uma espécie de consenso de evidência, que faz dos laços entre a escola, a transmissão dos saberes e a história um momento fundador da República e da identidade nacional, é sem dúvida porque as funções sociais da história na escola, na França, têm uma longa história.

As principais finalidades do ensino da história, regularmente enunciadas a partir da segunda metade do século XIX, são de várias ordens. A primeira delas é moral. Como mostram Patrick Garcia e Jean Leduc (GARCIA, LEDUC, 2003), desde o século XIX até hoje, a história da França visa dar como exemplo grandes personagens representativos do universal francês ou encarnar os valores da República e os ideais franceses. A segunda finalidade visa promover um modelo de socialização. Integrar-se na nação passa pela aprendizagem da história, e por isso ela está investida de uma missão de identidade. Eis toda a história da escola, do século XIX até a segunda metade do século XX. É em torno de uma forma escolar do discurso histórico que é costume desde então designar pela expressão "romance nacional", que desenvolveu para si todo um conjunto de figuras, de temáticas que visam trazer à luz "valores universais que se expressam tanto por sua influência cultural nos séculos XVII e XVIII quanto pela dos ideais da Revolução Francesa e da Declaração dos Direitos do Homem e do Cidadão." (GARCIA, LEDUC, 2003, p. 275) Em torno de temáticas mui amplamente propostas por Michelet, mas também por Renan, o Segundo Império e depois a Terceira República farão que se difunda um ensino próprio a fundar uma "consciência francesa". A fórmula "Tu deves amar a França porque a natureza a fez bela e a sua história a fez grande", que era preciso aprender de cor, ressoa hoje como a herança mais sintomática de Ernest Lavisse e de seus manuais, regularmente reeditados com sucesso constante. No fundo, uma história sagrada da França e da pátria teria substituído a história santa, pela "transferência do divino à história nacional”, pois “somente a história está qualificada para atingir o essencial da identidade da França”. (DETIENNE, 2010, p. 127)

Esta noção de "romance nacional” não é específica da França (CABANEL, 2007). Nos últimos anos, muitos pesquisadores em todo o mundo foram levados a falar sobre a maneira pela qual cada nação (a sua própria, na maioria dos casos) se contava. Quer se trate do Chile (MAYORGA, 2010), de Israel (BEN AMOS, 2010) ou da Bulgária (DEYENOVA, 
HEIMBERG, LOUBES, 2013). Propondo, a exemplo do "romance familiar" da psicanálise, um discurso com suas dobras e pregas, com suas glórias e seus traidores, com o que se pode dizer e o que se cala, suas hipermnésias e seus recalques ou ocultamentos (CONAN, ROUSSO, 1996), a escola oferece uma narrativa coerente do passado da nação, criando o contínuo narrativo no descontínuo da história, mantendo a ilusão genealógica da unidade histórica do comum, da unidade do que faz o "nós" das nações. Cada entidade política, na era das nações do século XIX, teve a vontade de "inventar a tradição" (HOBSBAWM, RANGER, 2006) para “comunidades imaginadas" (ANDERSON, 2002).

Portanto, implicada assim na construção tanto do político quanto do nacional, a finalidade cívica do ensino da história constituiu-se durante muito tempo em um objetivo central, mesmo antes da Terceira República (BRUTER, 1997). A história ensinada é comumente reconhecida como a garantia de uma formação cidadã, permitindo, por um lado, a construção de um espírito crítico para agir na sociedade de maneira livre e responsável, e, por outro, criando uma cultura cívica comum ao conjunto dos futuros adultos escolarizados na França. A história forma o cidadão. É uma espécie de topos da disciplina.

Significa isso que a finalidade cognitiva, intelectual, acadêmica está ausente da problemática francesa? Certamente que não. As finalidades intelectuais sempre estiveram no cerne do dispositivo escolar. A escola considerava e ainda considera que a história é uma soma de saberes que devem ser dominados, até mesmo nos movimentos da historiografia, mas também dos conhecimentos práticos do raciocínio, da exposição dessas ideias: em suma, uma espécie de arte do historiador declinada à francesa...

Há vinte anos, no entanto, a questão do ensino de questões delicadas da história surge nos debates escolares, públicos e políticos franceses. Acompanhando nisso os debates em torno das questões de memórias, as atividades de sala de aula estão sujeitas à interrogação de uma sociedade inteiramente convidada a examinar o interior da escola 
e de seus conteúdos de ensino da história, a fim de ver nele ocultamentos, omissões ou amnésias nacionais.

Se olhássemos rapidamente para esta atualidade memorial em plena renovação (BONAFOUX, DE COCK, FALAIZE, 2007), seríamos tentados a ver nela uma verdadeira revolução, ou pelo menos uma ruptura com o passado da disciplina histórica e do seu lugar na escola francesa. Desde a publicação do livro de Suzanne Citron, Le Mythe national (CITRON, 1989), é o romance nacional que parece fragilizado, questionado e reavaliado sob uma nova luz. Não há volta às aulas, ou uma atualização memorial ou legislativa, sem que os conteúdos de história abordados na escola, ou mesmo a maneira de contar a história da França, sejam questionados, interrogados e ordenados a dar conta dos traumas do passado nacional.

Esta virada memorial que data dos anos 1980 pode ser observada nas prescrições escolares e nas veleidades regulares do legislador de influenciar a sua escrita. Ela pode também ser vista nos conteúdos dos manuais escolares, objetos escolares tornados a tal ponto referência, que nenhuma editora, hoje, vê sem apreensão o momento de se aplicar aos capítulos dos temas considerados delicados. Do mesmo modo, a eficácia das lições apresentadas em sala de aula, no dia-a-dia da escola, traduzem esta virada memorial dos últimos 20 anos. Em que ensinar esses temas delicados para a sociedade francesa ou europeia (vê-se como em toda a Europa as mesmas questões são colocadas) se constituem em uma ruptura na ordem escolar ordinária?

A história inteira tornou-se um desses temas delicados, uma dessas questões vivas do ensino que Alain Legardez e Laurence Simonneaux evocam em seus trabalhos sobre a didática das disciplinas ensinadas (LEGARDEZ, SIMONNEAUX, 2006). Para eles, um tema de ensino é vivo quando reúne diversos fatores. O primeiro tem a ver com a vivacidade da questão em toda a sociedade, especialmente se o tema abordado em sala de aula está presente intensamente nas mídias e são objeto de controvérsia. O segundo está relacionado aos debates interiores à disciplina. Claramente a Revolução Francesa foi por muito tempo um campo de debates historiográficos que fizeram desta questão de história uma questão viva. E, finalmente, para caracterizar a "vivacidade" de uma questão de ensino, é preciso também, de acordo com esses autores, que ela seja delicada em sala 
de aula, quando o próprio professor pode ser colocado em dificuldade no que diz respeito aos conhecimentos necessários para ensinar como em função das reações dos alunos.

\section{República, trauma e ensino}

Por ocasião desses debates memoriais muito carregados de desafios e implicações na França e em outros países da Europa, o historiador Pierre Nora utilizou frequentemente a fórmula que diz que, além do silêncio, da amnésia por vezes saudável, “a memória divide, a história reúne”. A história existiria para dizer a verdade, ou pelo menos fazer justiça das querelas de memórias que cada comunidade nacional ou europeia poderia alimentar. Hoje, nas salas de aula da escola francesa, o curso de história também divide. De fato, o curso de história sempre dividiu. Nas regiões hostis à Revolução Francesa, os professores da República tiveram mui frequentemente que empreender uma luta cerrada para fazer ouvir a voz de uma Franca republicana, ao risco de fazer calar os massacres da revolução, ao risco de uma unanimidade de fachada. Mas ao longo do caminho, com a ajuda do tempo e das provas do tempo nacional, um discurso consensual, ou com a aparência de tal, foi capaz de se desenvolver, especialmente em torno dos anos de 1945-1965, para o benefício de uma libertação e de uma reconstrução inteiramente sujeita ao progresso social dos Gloriosos Trinta. Certamente, os debates sobre a União Soviética e sobre a natureza do comunismo foram capazes de alimentar as controvérsias escolares desses anos, até os anos 80. Mas hoje, passados já quinze anos, a história ensinada divide também, como no tempo das lutas pela fundação da República. As turmas conhecem uma série de incidentes difíceis de medir estatisticamente em sua magnitude real, mas cujo testemunho permite avaliar a perturbação ou desconforto dos professores de história, e não apenas, ante temas de interesse para a história nacional e, portanto, para a identidade francesa. Por um lado, parece difícil para os professores de história definir um romance nacional que tenha a mesma força integradora daquele produzido antes da década de 1970 na França. Nenhuma narrativa coerente veio substituir o romance nacional com uma visão teleológica baseada na monarquia, no 
ensinar, de sua didática, inclusive pelos alunos. Portanto, dificuldades ontológicas, mas também práticas, que interrogam hoje não só a escola, mas também toda a sociedade. Tudo se passa como se, na escola francesa, as práticas estivessem longe do que Paul Ricoeur chamava de o exercício de uma “justa memória”, isto é, a capacidade de elaborar uma conjunção respeitosa e harmoniosa da história e da memória, até e inclusive na pedagogia como na didática.

Os traumatismos da história nacional se inserem em eventos angustiantes. Eventos com sofrimento individual, familiar e coletivo em sentido amplo. Do genocídio armênio à Primeira Guerra Mundial, das repressões coloniais à Segunda Guerra Mundial, em que o evento paradigmático do trauma no século $\mathrm{XX}$, a Shoah, figura como paradigma. O extermínio dos judeus europeus é o evento em proporção do qual toda memória contrita tenta comparar o seu destino. De certa maneira, a história da imigração na França também traz consigo elementos traumáticos, tantos são os seus lutos reais, materiais e simbólicos, e a fortiori quando essa imigração majoritariamente pós-colonial é realizada em um contexto de humilhação. Deste ponto de vista, a história francesa de imigração dos harkis após a guerra da Argélia é sintomático do que queremos dizer com trauma em história. O evento acontece no contexto colonial e se estende na metrópole e na Argélia independente por um duplo processo de rejeição. Confinados em campos, entre os quais o de Rivesaltes, ou instalados em vilas ou aldeias, os auxiliares do exército francês e suas famílias tentam sobreviver à desonra, às restrições e às discriminações. $\mathrm{Na}$ Argélia, morrem a balas vingadores dos que buscavam acertar contas após a guerra.

Como falar sobre o trauma em sala de aula sem cair, em história, na escrita do pathos, afastada dos cânones científicos da escrita da história? Como falar sobre as feridas aparentes ou simbólicas das populações feridas, sem ignorar o frio (e necessário) distanciamento dos fatos e dos documentos por vezes em contradição com as memórias tais como elas são transmitidas de geração em geração e tais como podem expressar-se em sala de aula? O conceito de "memórias traumáticas" tem sentido? Esta tensão entre o 

momentos dramáticos da história.

De fato, desde o fim da Primeira Guerra Mundial, e depois do inferno das trincheiras e da "carnificina", os militantes pacifistas brandem o "isso nunca mais" desde então repetido sistematicamente. Desde o pós-guerra, o modo como se fala sobre o horror do acontecimento passa pela narrativa, seja autobiográfica ou literária. Henri Barbusse, Erich Maria Remarque são as expressões mais conhecidas. Pois no desejo de ominar o evento em toda a sua violência, porque não se pode compreendê-lo plenamente, a passagem pela narrativa é fundamental. Reunindo-se em congressos de ex-combatentes até bem tarde no século XX, os "poilus" refazem o evento por meio da fala, colocando em palavras as lembranças. Esse fenômeno se expressa hoje com uma força dez vezes maior em torno daquilo que se convencionou chamar na França de “implicações de memória”. Iniciados pela liberação de fala dos anos 1980 sobre a Shoah, as narrativas que repetem o evento traumático se multiplicam. Contra o recalcamento da memória, os contemporâneos acreditam implícita ou explicitamente que a repetição pela palavra, pela narração, pela forma narrativa, permite pensar (nova forma do sagrado?) que se poderá evitar a repetição do ato. Mais ainda, ordena-se à história falar sobre a dívida, em um reconhecimento da humilhação sofrida, para uma reparação simbólica (e não apenas) dos males sofridos no passado. Ao contrário do que dizia Marc Bloch, para quem fazer história é entender, mas nunca julgar.

A maneira pela qual a história é chamada a falar sobre a vitimização, a falar sobre o horror da história, coloca um problema para a França na expressão escolar de sua narrativa nacional. Até os anos 1970, a história da França se apresentava no modo da homogeneidade e da coerência dirigida ao futuro (glorioso ou não). A França tinha os seus territórios, seus campanários rurais, seus heróis positivos e parecia querer brilhar no mundo graças à sua cultura e aos seus valores humanistas e revolucionários (os Direitos do Homem), mas também graças aos seus territórios coloniais. Desde o final dos anos setenta, e concomitantemente, em (des)favor da descolonização, do retorno da memória 

amanhãs que cantam aos ontens que descantam.

As pesquisas que foram conduzidas durante mais de dez anos no Instituto Nacional de Pesquisa Pedagógica - INPP permitiam determinar melhor o que constitui as dificuldades escolares relacionadas aos temas delicados, sensíveis ou controversas da história europeia recente. Elas fazem parte de um campo de pesquisa cada vez mais armado teoricamente, especialmente nos últimos anos, na área do ensino (TUTIAUXGUILLON, N., e NOURISSON, 2003) e da sociologia do currículo (LANTHEAUME, 2003). São as conclusões preliminares destas pesquisas em andamento, e é possível propor algumas de dessas conclusões preliminares, mas também reler um estudo realizado na Academia de Versalhes, entre 2000 e 2003: Entre mémoire et savoirs : l'enseignement de la Shoah et des guerres de décolonisation (CORBEL, FALAIZE, 2003).

\section{Uma investigação que levanta a questão dos limites das pesquisas em didática}

A pesquisa que conduzimos se desenvolveu em um contexto muito particular. As entrevistas se inseriram numa época histórica particularmente fecunda e rica de "ecos do passado". O tempo da investigação foi o do contexto político e internacional particularmente rico e carregado de significado, inclusive para o objeto que escolhemos. A persistência do conflito na Palestina, suas convulsões repetidas e a acentuação dos combates, o 11 de setembro de 2001, a volta à França da memória da guerra da Argélia, tendo em primeiro plano na mídia as acusações de tortura feitas em relação a vários membros do exército francês, os debates historiográficos em torno de duas teses recentes de Raphaëlle Branche (BRANCHE, 2001) e Sylvie Thénault sobre a história da Argélia (THÉNAULT, 2001), o “choque” político de 21 abril de 2002 com o Front National e Jean-Marie Le Pen no segundo turno das eleições presidenciais, o início da guerra no Iraque na primavera de 2003 e todos os debates desde 2002 sobre o antissemitismo nas escolas, e, em 2003, o ressurgimento dos debates sobre o véu... foram os temas de 
da nossa investigação. É um dos elementos para compreender o que está em jogo na sala de aula quando são mencionados pelos professores, seja qual for o seu nível de exercício e disciplina, "temas delicados" da história do século XX.

Mas há outro elemento de contexto que tem a sua importância: o dos debates muito presentes na França nos últimos 15 anos, entre "republicanos" e "pedagogos"; como parte de um debate caricatural conduzido supostamente para fazer oposição a uma transmissão escolar frontal e a uma tendência construtivista da apropriação dos saberes. A investigação se desenvolveu no momento do apogeu desta controvérsia pedagógica, que não está sem relação com o tema da transmissão da história. Pois houve a tendência a opor a transmissão de uma narrativa nacional tradicional à construção crítica, cidadã e democrática que a história propõe. Apesar de tudo, a propósito da Shoah, esta oposição poderia verificar-se difícil de distinguir. O que colocar em debate (como saberes) e qual a negociação de sentido para o extermínio se pode discutir, como parte de um ensino crítico? A autoridade do saber científico não permite premunir aqui um relativismo eventual? Entre o modelo narrativo mítico e o modelo construtivista crítico, talvez haja um caminho do meio em que um dos dois modelos não se sinta excluído do outro.

\section{"Ensinar a Shoah"? Aulas não como as outras}

Como abordar a Shoah na escola? Como "fazer conhecer a Shoah na escola" (BORNE, 1994)? É preciso ensinar a Shoah ou "ensinar sobre a Shoah? (LECOMTE, GIACOMETTI, 1998)? "Como educar contra Auschwitz" (FORGES, 1997) na escola francesa? E ainda, como não "pedagogizar" (SCHNUR/ERNST, 1997) a Shoah com o risco de relativizar o acontecimento ou, ao contrário, sacralizá-lo? Tantas interrogações que, há uma década, estão no cerne dos questionamentos pedagógicos dos professores do secundário e, doravante, dos professores das escolas a partir dos novos currículos da escola primária de 2002. Como dar conta do irremediável? Como falar sobre o horror do 

perder, na relação pedagógica a sua dimensão de indizibilidade?

De maneira geral, e é a primeira constatação da pesquisa realizada, havia nas práticas uma real e significativa tensão entre o dever de memória e a necessidade de dizer a história. O logos da verdade contra o "lembra-te" da fidelidade e do afeto: eis a tensão mais pronunciada que percorre o conjunto do ensino da história na escola francesa nos dias de hoje. E entre os temas que ocupavam o horizonte moral do "lembrate" e a esfera ontológica do reconhecimento, o extermínio dos judeus da Europa constitui a sua matriz paradigmática, uma espécie de modelo em que se experimentavam as didáticas da história. Uma dimensão de compaixão se instalava muito frequentemente: os bons sentimentos, as oposições simples (judeus/vítimas; nazistas/carrascos), a ausência da "zona cinza" (Primo Levi), e sobretudo uma emoção que submerge. Se todos os professores de história diziam colocar em cena um saber crítico e um método rigoroso, a aula e a avaliação que era feita (quando era feita) remetia mais ao exercício de um dever de memória do que a um trabalho de história. A rememoração não nunca estava longe, em lugar da lição de história.

Essas tensões didáticas implicam toda uma série de práticas de aula específicas, que passam pelo recepcionamento de testemunhas, pela visita de "lugares de memórias", pelo uso sistemático e muito frequente do filme: no fundo, sobre esse tema em particular, e de modo amplo, os professores fazem dessa aula de história um momento importante do ano, "uma aula não como as outras", momento em que para muitos o ensino da história encontra toda a sua razão de ser. Desta disposição específica e simbólica da aula no meio do ano escolar, desta disposição deste momento importante em cuja ocasião os professores frequentemente inventam práticas, como relações com os alunos, ou testam novos dispositivos didáticos, os alunos deduzem que esta aula é carregada de uma dimensão excepcional, talvez sagrada.

Isto é reforçado pelo fato de que essas aulas são frequentemente a ocasião de fazer a educação cívica, explicitamente. O extermínio ocupa então o lugar do inverso 
presente implicitamente na organização das atividades da aula. Dito de outro modo, esta função cívica deste ensino tem duas consequências diretas: a primeira é fazer da Shoah uma questão moral, ou a história mesma parece relegar para longe da aula; a segunda é reformular indiretamente a função conferida ao heroísmo no currículo francês. Enquanto, por muito tempo (desde Jules Ferri, de facto), o heroísmo era dirigido ao futuro, todo aureolado da glória do passado, encarnado por personagens que deviam representar a França em todas as suas tradições, o heroísmo atual passa doravante por uma moralidade do sofrimento das vítimas: os heróis positivos de ontem são substituídos por uma heroização das vítimas do passado.

Neste esquema memorial da aula de história, tal qual funciona desde que a França encontrou a sua memória no que diz respeito a Vichy e à deportação dos judeus da França (ou seja, há apenas quinze anos), as aulas de história se chocam com reações de alunos que vêm minar literalmente o pacto pedagógico que existe entre professores e alunos. A investigação realizada na Academia de Versalhes de 2000 a 2003 confirmou o que outros já tinham pressentido.

\section{As dificuldades próprias do ensino da Shoah}

Cinco dificuldades mais significativas puderam ser identificadas com exatidão suficiente. A primeira está ligada ao perigo que poderia constituir uma forma de sacralização do tema, sem a contrapartida de um espírito crítico. Muitos professores temem esta fixação dos papéis sem exame: carrasco versus vítimas, que eles próprios, no entanto, contribuíram a instalar e a manter. Não é no sagrado que se constrói a história racional, o logos da verdade, temem aqueles que veem os seus limites efetivos na intimidade de sua aula.

A segunda dificuldade diz respeito à vitimização dos judeus, e pode ser estendida a todo grupo visto pelo ângulo do seu único lugar doloroso na história. Isto se relaciona, 
história senão no momento do seu extermínio, ou (mas isso serve de consolo?) no momento do caso Dreyfus. As questões são inúmeras e são conhecidas desde que a historiadora especialista na memória do extermínio, Annette Wieviorka, as formulou nos anos 80: como identificar-se com os mortos? Como identificar-se com aqueles que não tem existência senão na vitimização da sua posição social e histórica? É o sentido das reservas feitas nesses últimos anos sobre as viagens escolares a Auschwitz, com alunos muito jovens às vezes. O que eles podem entender, sentir? O sentido da viagem, que acontece às vezes no espaço de um só dia, por condições de execução que se deixam às vezes rever, nem sempre é legível.

A saturação dos alunos relativamente a este tema representa uma terceira dificuldade. Dificuldade quase impossível de analisar, de tal modo ela vem contradizer o conjunto dos objetivos pedagógicos, e age quase em sentido contrário à intenção docente. Contrariamente ao que se pensa frequentemente, este fenômeno não é recente. Já em 1982, Annette Wieviorka falava de saturação, em aula, após o atentado da rua Copernic, e sobre o tema do antissemitismo. No esforço de dizer o inefável, a organização do currículo faz de tal modo que os alunos ouvem falar da Shoah, e frequentemente de uma maneira similar desde a escola primária até ó ensino médio. Não similares nas informações históricas trazidas, mas similares na tonalidade e na emoção da aula. E frequentemente em várias disciplinas, em letras e até em filosofia. Portanto, a Shoah se torna esse topos que deve servir ao professor. É o que um professor de filosofia no último ano chama de "o esmagamento da referência”. De tanto falar disso, e demais, ou mal, passa-se ao lado do ensino tal como ele deveria ser feito. Uma explicação para isso pode ser dada pelo fato de que muitos professores que têm mais de 37 ou 38 anos (ou seja, a maioria deles) descobriram a questão dos judeus sob Vichy quando faziam seus estudos de história na Universidade, ou mesmo já estavam trabalhando, no que diz respeito aos mais velhos. Inevitavelmente, sua vontade de falar deste período doloroso 
da história nacional e europeia se acha decuplicado, pelo menos a vontade daqueles para quem o tabu escolar existiu.

Uma quarta dificuldade vem de um efeito de relativização de certa concorrência das memórias que se instalam em aula. Os alunos percebem muito bem este investimento docente a propósito desse tema, que eles traduzem em um sentimento de superinvestimento, à custa de outros temas dos quais os alunos, aliás, já têm conhecimento: o genocídio tútsi na Ruanda, a questão armênia, a colonização... De fato, esses temas são menos abordados em aula e deixam frequentemente os alunos com um sentimento de injustiça: haveria portanto "um sofrimento mais legítimo do que outro". Este sentimento prejudicial ao estudo da Shoah é fonte de confusão nos alunos, sem que possa ser necessariamente desfeito pelos professores, às vezes sobrecarregados ou ultrapassados. Injustiça, incompreensão às vezes, mas também provocação. E é a quinta dificuldade que os professores encontram quando os alunos fazem abertamente reflexões antissemitas. Daí, dois olhares se enfrentam, tanto quanto duas gerações: o professor que é um adulto numa relação de autoridade e o aluno que joga com a provocação.

Aliás, quinta dificuldade, a investigação mostrou a que ponto os professores podiam às vezes ser incapazes de responder às reivindicações de identidade dos alunos, tanto quanto aos discursos políticos ou antissemíticos sustentados por eles. Por toda uma série de razões que se ligam essencialmente à sua cultura histórica, jurídica ou sociológica, poucos têm condições de responder às provocações de alunos que usam o conflito entre Israel e Palestina como uma arma contra o discurso dos professores.

No fundo, se tentarmos refletir com Alain Legardez sobre o ensino dos temas delicados em sala de aula, deveremos retomar a sua tipologia das características das questões socialmente vivas em sala, características que representam igualmente riscos. A primeira está ligada à legitimidade, por um lado, do saber mobilizado pelo professor que pode vir chocar os alunos, que devem aceitar ao mesmo tempo o aprendizado de um saber que pertence à escola e a integração deste saber com seus próprios esquemas mentais (o que a didática chama de saber social dos alunos). Entre essas duas referências aos saberes, tensões imediatas e até mesmo colisões podem acontecer. Legitimidade, 

apenas aos alunos. ("Aí não, sobre a Shoah, não são aulas como as outras, não é possível. Eu sou, como dizer... desapaixonado pela guerra da Argélia. Ainda que, ao mesmo tempo, é mais a paixão dos alunos que eu vou encontrar. Enfim, para mim, estou mais numa relação... de confronto com uma paixão muito forte diante de mim. Enquanto que sobre a Shoah, a paixão vem por si só." - Entrevista n. 39, História, Ensino Médio)

A segunda característica didática do ensino das questões socialmente vivas a que me aterei é precisamente a dos riscos. Riscos para os alunos de ter que integrar este saber erudito e escolar apesar do seu saber social que pode opor-se a ele firmemente: "Não estou entendendo nada, senhora. Em casa, eu assisto à Al Jazira e eles dizem que os judeus oprimem os palestinos, e agora, com Primo Levi, é de fato uma injustiça o que fizeram com os judeus". Risco também para os professores, pois os riscos da profissão, de fracassar numa aula, são tanto mais sérios quanto se trata de uma questão potencialmente viva, com práticas menos rotineiras, menos seguras, ou se elaboram majoritariamente didáticas inovadoras, contrastando com o cotidiano do trabalho durante o ano.

\section{Pode-se ainda ensinar sobre o extermínio dos judeus na França...}

Contudo, o relatório de pesquisa do INPP sobre a Academia de Versalhes permitia nuançar o que um debate midiático exprimia nesta fórmula sobre os "territórios perdidos da República", uma espécie de territórios que se tornaram hostis a qualquer ensino, lugares urbanos antissemitas e arredios a todo ensino da Shoah. O que o filósofo Alain Finkielkraut não cessou de denunciar. A realidade estatística pelo menos é outra. Se há estabelecimentos escolares na Franca que enfrentam dificuldades sérias quanto aos conteúdos de ensino e aos aprendizados, parece que na maioria dos casos, inclusive nos bairros ditos “delicados" ou “difíceis", equipes de professores cumprem a sua tarefa sem 
dificuldade maior do que aquela já existente no cumprimento de sua missão educativa em face de um tema desta natureza.

Mas este o fazem com toda consciência das implicações globais deste ensino. É, de resto, sem dúvida em letras que este ensino dos temas delicados é assumido da melhor forma. Talvez porque, pela literatura, os professores têm o hábito de assumir a emoção suscitada pelos textos e, portanto, a dos alunos. A coerência didática se organiza segundo um regime de verdade própria à disciplina.

Se se aceita o quadro teórico que Develay (DEVELAY, 1995) propõe, segundo o qual "a didática considera que a particularidade dos saberes ensinados determina modos de aprendizagem e modalidades de ensino particulares", então é preciso examinar atentamente o que Alain Legardez (LEGARDEZ, SIMONNEAUX, 2006) propõe quando evoca vários caminhos para ensinar os temas delicados: o primeiro é apoiar-se incessantemente em uma problematização, cuidando para transpor assumidamente o conteúdo mais rigoroso em uma didática segura; estando ao mesmo tempo consciente de que a problematização reforça o lado "quente", e mesmo "fervente" do tema. O segundo caminho é desempenhado na questão das relações com os saberes, que supõem (nós o havíamos observado no relatório de pesquisa da Academia de Versalhes) um domínio não somente dos objetos históricos, dos conteúdos, mas também das implicações jurídicas e sociológicas desta questão, assim como um domínio das representações dos alunos e da sociologia exata dos alunos confiados à escola.

\section{Conclusões revisitadas em função das questões memoriais de hoje}

De fato, as questões relativas às tensões entre história e memória na Franca se deslocaram ligeiramente. Quatro estudos do INPP permitiram medir esse fato. Uma hipótese pode ser avançada agora: Vichy, a deportação e o extermínio dos judeus da Franca e da Europa já não constituem um tema controverso, no sentido de "um passado que não passa". Isso não quer dizer que as dificuldades didáticas não persistam. Mas elas não são o objeto de um relativo consenso agora no conjunto do sistema escolar. Além disso, inúmeros e notáveis trabalhos históricos, museus, livros de testemunhos, referências cinematográficas numerosas permitem dotar os professores de recursos 
concorrência, das histórias plurais que compõem o romance nacional que não se confessava, há apenas vinte anos, tão diversos, e para terminar, o passado colonial da França.

Para cada uma das investigações do INPP, traços dominantes comuns podem ser sublinhados, aparentando-se a constatações de conjunto: primeiro, as prescrições oficiais. Ao analisar os programas da educação nacional de maneira exaustiva, mas também as circulares e os debates públicos realizados sobre questões de história e de memória em sala de aula, surpreendemo-nos com o aumento significativo desta problemática nas decisões institucionais relativas ao currículo. Quer seja sobre o genocídio armênio, quer sobre a colonização, e mais recentemente também sobre a história da imigração, desde os anos 2000 mais ou menos, o ministério e as comissões curriculares parecem ser particularmente sensíveis às implicações memoriais. A evolução em direção de uma inclusão das páginas de história não suficientemente abordadas até então em sala de aula.

Incontestavelmente, a mesma constatação pode ser feita em relação à escrita dos livros didáticos. Ao ler e ao analisar os manuais escolares da escola primária e do secundário, sobre o conjunto dos temas delicados da sociedade francesa, que são temas de história, as pressões memoriais pesam com todo o seu peso. A nova presença de duas páginas sobre temas que até então tinham, quando muito, 200 ou 300 palavras, testemunha isso amplamente.

Da mesma maneira, observa-se uma inflação de oferta ou de projetos de ferramentas pedagógicas destinadas aos professores no que diz respeito a temas como a colonização, a imigração ou a escravidão.

Permanece a questão das práticas. As investigações que começam deverão evidenciar o que muda ou permanece inalterado nas práticas efetivas da aula de história. Em que medida as implicações memoriais influem na maneira de falar sobre a história 

aos alunos e às razões que impõem hoje fazer uma outra história da França em sala de aula, esconde-se a questão das crianças que reconhecemos como provindas da imigração e de outra religião. No fundo, é o retorno da questão religiosa que permeia o sistema público de ensino. O retorno é perceptível nos debates inumeráveis e por vezes acirrados realizados no seio da educação nacional acerca da lei de 2004 sobre a laicidade em ambiente escolar; situamo-lo também nas categorias de designação dos alunos que pendem cada vez mais para categorias religiosas (crianças "muçulmanas", "alunos judeus"...); mas ele se encontra também nas reivindicações dos alunos, que podem colocar o Islã como elemento de uma construção de identidade de revalorização deles mesmos e da sua família de imigrantes.

\section{O pós-colonial em questão}

A colonização, a escravidão e a imigração mantêm relações históricas numerosas e complexas. A história do fenômeno colonial na longa duração conheceu a escravidão sem reduzir-se a ela, e a imigração em parte ligada à colonização, sem que esta seja a sua única fonte. A presença delas no sistema escolar francês não faz parte da mesma história nem é da mesma natureza.

A colonização sempre fez parte do currículo escolar, contrariamente ao que é dito às vezes sem um prévio exame. Ela sempre fez parte do currículo e dos livros didáticos tanto da escola primária quanto da secundária. Ela chegou a constituir uma das dimensões fundamentais das aprendizagens de história na Terceira República, uma espécie de matriz ideológica da propedêutica cidadã dos alunos franceses, desde os anos de Ferry até os anos 1950-60. A colonização fazia parte do projeto francês e, portanto, do projeto de educação cidadã dos alunos franceses. Desde a escola de Jules Ferry, o projeto colonial era narrado ao vivo em numerosas turmas escolares francesas, à medida das conquistas e do avanço das tropas coloniais. A dupla Bugeaud/Abdel Kader, por exemplo, 

acompanhou o cotidiano escolar das turmas até os anos 1960. A República se gabava das colônias na sua dimensão de civilização e de progresso, tais como os manuais da escola primária podiam fazer até uma data recente da história escolar: meados dos anos 1960 (EIZLINI, 2007). O tempo das colônias permitia ler a "grandíssima França”, “o progresso realizado em todas as áreas", assim como o prestígio de uma França presente em todos os cantos do mundo. No fundo, não se pensava a República sem as colônias.

A evolução da inserção do espaço colonial nos manuais escolares e nos programas (LANTHEAUME, 2002) permite medir igualmente o que foram capazes de ser as mudanças operadas no universo escolar. Françoise Lantheaume analisa três evoluções mais significativas da escrita dos manuais escolares. A primeira reside no que ela chama de papel refrigerante da questão desempenhado pelos autores dos livros. Esta refrigeração das implicações, posta em operação nos livros escolares, se faz pela disseminação do objeto em vários níveis de classe, dissociando a colonização das lutas de descolonização. O ocultamento de temas mais significativos da colonização é evidentemente outro meio de refrigerar a questão. A violência colonial, por exemplo, se ela é descrita, heroizada e valorizada até os anos sessenta como a marca da civilização francesa que se afirma, inclusive pelas armas, ela tende progressivamente a ser expressa por eufemismos, relegada à explicação e no fim das contas acaba por ser pouco estudada. Da mesma maneira, o racismo colonial que Pierre Vidal-Naquet denunciava quase nunca é apresentado na sua particularidade e nas suas manifestações ideológicas e cotidianas. No fundo, a evolução da escrita dos manuais dirigiu-se lentamente para uma moralização do conflito colonial: a violência é, desde os anos 80, vista com neutralidade. A crítica razoável e aparentemente confiável ou objetiva (pela profusão dos documentos apresentados) da colonização se faz pela crítica dos excessos, tanto dos colonos quanto dos partidários da FLN, por exemplo. Esta moralização impede às vezes de pensar a história com toda a sua complexidade, mas tem o mérito prático de refrigerar a questão em torno dos valores sobre os quais o acordo pode ser feito. 
Se há, de fato, um tema que não variou em sua apresentação escolar, pelo menos do ponto de vista da tonalidade moral da sua apresentação, é a questão da escravidão e do comércio negreiro do Atlântico. É usual dizer que a escola francesa não fez nada e não disse nada sobre a escravidão. É frequentemente um efeito de olhar cronológico de pequena escala (FALAIZE, 2009). Após 1945, talvez em razão das ressonâncias morais que o tema podia ter no momento em que se denunciava com o termo de escravidão os crimes dos nazistas na Europa, o comércio negreiro era apresentado nos manuais de história, tanto do primário quanto do secundário, nos capítulos dedicados à política mercantilista e colonial de Colbert (principal ministro do rei Luís XIV). Os livros do primário, por exemplo, abordavam esta questão quando tratavam do ministro do rei, Colbert, e do grande comércio, numa escrita tipicamente colonial: "Nossas Antilhas estavam florescendo; mas era a custo de uma vergonhosa escravidão." (GRIGNON, 1950) O Código Negro e o Comércio Negreiro são apresentados em parágrafos frequentemente autônomos, assim como Toussaint Louverture, general dos exércitos da Revolução Francesa. Com efeito, principalmente após a publicação dos novos programas do primeiro ciclo do ensino secundário de 1969 (para os alunos de 13 a 14 anos), os textos oficiais incitam os professores a abordar a questão da escravidão em suas aulas. O lugar do açúcar considerável nas trocas do Antigo Regime e a parte da riqueza colonial na balança comercial do reino francês era a ocasião de apresentar em desenvolvimentos por vezes longos o comércio triangular, a escravidão nas plantações e a situação imposta aos negros. O manual do $4^{\circ}$ (para os alunos de 13 anos) de Pierre Milza e Serge Berstein, publicado em 1970 para o colégio (MILZA, BERSTEIN, 1970), mostra a importância que este tema podia ter. É difícil dizer até que ponto ele era estudado nas aulas, mas parece que a política mercantilista de Colbert (hoje muito esquecida pelos programas e manuais) sempre foi a ocasião de desenvolvimentos mais ou menos longos, mais ou menos precisos, sobre este tema, com os alunos, principalmente na escola primária.

No fundo, a retirada relativa desta temática do ensino data dos anos 80 . Ela se faz em favor (ou por causa) de dois fatores principais. O primeiro se liga ao fato de que toda uma história tradicional da França desaparece progressivamente. Roland (o de Ronceveaux; batalha perdida pelos Carolíngios em 778, contra os Vascões. Esta batalha se 

sem fortuna, ele participa das guerras da Itália. É descrito nos livros didáticos da Terceira República como "sem medo e sem reproche") e outro Colbert já não fazem parte necessariamente dos personagens emblemáticos da história nacional. A hora é da política e da análise da monarquia absoluta. Bossuet substitui Colbert, o ideólogo substitui o ministro. A análise do conceito político substitui a glorificação pela anedota do empregado do Estado, trabalhador e fiel. A outra razão que se erraria em menosprezar é a forma mesma dos manuais escolares: dos anos 1970 aos anos 1990, os livros didáticos do secundário perdem talvez mais da metade, talvez até dois terços dos seus conteúdos em caracteres. Isto significa que a parte reservada ao texto se apaga diante daquela destinada aos documentos. Escrever em 12000 caracteres o "desenvolvimento colonial” do século XVIII, como fez Pierre Milza e Serge Bernstein, ou escrever em apenas 3000 caracteres hoje (ainda!), não é a mesma coisa. Escolhas são feitas, e como o mapa do comércio triangular subsiste como um documento patrimonial da escola e da publicação escolar, os livros didáticos recentes escrevem a palavra "escravidão" no texto do autor remetendo ao mapa ilustrativo. Supõe-se implicitamente que o professor sabe, obviamente, o que é a escravidão. Esta postura talvez ilusória e prejudicial à análise razoável e crítica do fenômeno do comércio negreiro explica em parte o sentimento de fraqueza do tratamento do comércio negreiro nos manuais escolares.

Após a lei Taubira de 21 de maio de 2001, que visa a integrar melhor o estudo do comércio negreiro do Atlântico nos programas escolares, o relatório do Comité para a Memória da Escravidão mostra a necessidade de observar o mundo escolar com distância e discernimento. Certamente, não é possível “justificar em nenhum caso o lugar menor do comércio negreiro e da escravidão no ensino" (COMITÉ, 2005, p. 35); contudo, o relatório sublinha quantas editoras e quantos autores de manuais escolares prestam ouvidos à evolução da pesquisa, antecipando com frequência e amplamente as prescrições oficiais. É particularmente verdadeiro para as editoras dos manuais do ensino médio, entre 1996 e 2006: o desenvolvimento significativo do número dos documentos, 


\section{A história da imigração, um estudo de caso}

Entre os temas que têm a ver com a questão pós-colonial, a história da imigração apresenta, tanto na França como em muitos países da Europa, uma situação muito singular (FALAIZE, 2008). Até meados dos anos 1970, a escola francesa não levava em conta a questão da história migratória. É em favor dos agrupamentos familiares e do desenvolvimento das concentrações em torno dos espaços urbanos que os professores começaram a inventar práticas que levassem em conta a origem dos seus alunos. A história das famílias dos alunos provindos da imigração tomou conta do espaço escolar, priorizando a escola primária, a fim de dar conta da parte estrangeira da história nacional recente, fortemente ligada ao exílio pós-colonial. O desenvolvimento da história da imigração stricto sensu não se verificou verdadeiramente senão nos primeiros anos de 2000, em favor dos debates que presidiram à instalação na Porte Dorée, em Paris, da Cidade Nacional da História da Imigração. Muito recentemente, as editoras escolares, assim como os programas (primário em 2002, mas sobretudo os últimos textos para o ensino médio em 2008) integraram esta dimensão constitutiva da nação francesa.

Muitas práticas de sala de aula repousam, ou se apoiam, em um momento ou em outro, nas famílias dos alunos presentes à aula. Para evocar a história e as memórias da imigração, a escola recorre às famílias dos alunos presentes à aula, à sua história. Nas práticas de sala de aula, da escola primária ao último ano do ensino médio, tanto nas aulas de história como de literatura ou de ciências econômicas e sociais, costuma-se frequentemente pedir aos alunos que digam a sua "origem", "de onde eles vêm", seu “país de origem". Esta prática é tanto mais frequente, quanto se apoia na vontade de dar conta de uma particularidade que os professores desejam valorizar. Mais que isso, esta particularidade se torna objeto de ensino. Em algumas aulas, ensina-se a história da imigração, e em outras, e por vezes nas mesmas, opera-se uma inversão da ordem escolar, da relação pedagógica, em que já não é o professor que ensina aos alunos um 
conteúdo disciplinar, mas o aluno que ensina aos "outros" (os alunos da turma, o professor...) uma parte da sua história da imigração. Os professores se valem do estigma do aluno ("provindo da imigração”, “magrebino”, “muçulmano”, “imigrado”, “de origem diferente"...) para valorizar a diferença e a riqueza supostas que esta "origem" (como por magia) devia conceder-lhe. Trata-se, nem mais nem menos, de uma desconsideração social reconsiderada de um modo escolar, como uma reabilitação simbólica, como se se criasse uma "estigmatização positiva" de algum modo.

A atualidade e as implicações do presente são onipresentes na escola, quer se trate dos objetivos apresentados ou implícitos, das expectativas em relação aos alunos ou às finalidades que os professores atribuem ao ensino da história da imigração. A atualidade (política, do oriente próximo, econômica e social...) parece comprometer toda reflexão pedagógica, nas práticas mais cotidianas, sobre a história da imigração. Isto significa que ela vem exercer uma pressão sufocante para o objeto histórico: a dominação das outras disciplinas que não a história para abordar a história da imigração mostra isso. Tudo se faz em nome de um "aqui e agora". Os professores definem modalidades de fazer aulas e inserções disciplinares e temáticas mais em conexão com as preocupações que são as suas e que eles adivinham entre os alunos. O lugar dos debates recentes sobre a questão migratória e a identidade nacional, a abertura da Cidade Nacional da História da Imigração, os debates públicos (políticos e de associações) sobre a expulsão dos imigrados em situação administrativa irregular são temas de atualidade que assombram as consciências no mundo educativo, particularmente receptivo às noções de respeito, de tolerância e de abertura para o mundo, em conformidade com os termos mesmos dos diferentes programas, em todas as disciplinas.

De maneira geral, o tema da história da imigração é vivido, pensado e praticado na medida em que se trata de um objeto de história em torno do qual se organizam relações escolares, mas também sociais, entre "eles" e "nós"; entre alunos percebidos como "diferentes" e um "nós" coletivo da comunidade educativa e nacional. Uma história da imigração da qual os alunos seriam os portadores, em uma "estranheza" conduzida com generosidade e um profundo e sincero cuidado de reconhecimento, sobretudo em relação à história colonial francesa. Mas no reconhecimento de uma identidade dos 
história", vão muito frequentemente, certamente sem o querer, ao encontro de uma ideia de troca cultural que eles defendem em outros lugares: ao reificar a suposta identidade dos alunos que eles têm diante de si, eles fazem, em suma, uma concepção, e apenas uma, da identificação dos alunos e dissimulam a complexidade e a pluralidade das existências dos alunos. Aliás, e para acrescentar a esta confusão princípios norteadores da sua concepção pedagógica, os professores, tentados por tal procedimento de reconhecimento sem exame, em uma generosidade benévola e espontânea, "encerram" os alunos em um reconhecimento de grupo ("os alunos do Máli”, "os magrebinos"...) em que um olhar externo não pode ser colocado para ajudar esses alunos na adolescência, exatamente ao contrário de uma concepção dialógica da construção de identidade. $O$ relatório de investigação constatava que há algo que não foi pensado na história migratória da França que é veiculado pela escola e pela totalidade da instituição: e isto diz respeito não aos próprios imigrados, mas à própria nação e que faz do estrangeiro um outro irredutível, e do imigrado, ou de seus filhos, uma figura ambígua da questão nacional. Dos “outros", a escola não para de falar. Mas um "nós”, um "nós” coletivo nacional e construído em uma longa história, a escola tem, manifestamente, mais dificuldade em abordar ainda com serenidade.

\section{Para concluir}

Com certeza, ensinar os dramas do passado ou os temas controversos da história nacional marca uma ruptura com uma tradição francesa não só escolar, mas também acadêmica. Enquanto a história ensinada dava destaque aos ancestrais aureolados de glória e de sentimentos nacionais ou cristãos (o que, em alguns casos, não constituía senão uma só coisa), o retorno forçado no decurso dos anos 2000 dos debates sobre a história da França e as implicações de memória teve parte na dessacralização definitiva da Nação. 
A França saiu progressivamente de uma história imóvel, chauvinista, balizada por figuras heroicas cujo destino se confundia com o da nação. Podia-se apelar à emoção (e se fazia comumente) em torno de exemplos históricos por vezes distantes, como o martírio de Blandine (membro da comunidade cristã de Lião, Blandine foi aprisionada com seus correligionários, torturada e condenada à morte nas arenas de Lião/Lugdunum. Ela teria sido poupada pelos leões. Tornada símbolo para os cristãos, seu imaginário se afirma no século XIX e é retomado, quase exatamente, pela escola republicana anterior à Primeira Guerra Mundial. Ela figura entre os heróis franceses que a Terceira República celebra nas lições destinadas aos alunos, à través da produção editorial escolar). Esta emoção produzia em cada um uma relação patrimonial e mítica com o passado e contribuía para a edificação dos heróis nacionais. Se esta concepção do ensino da história foi vivamente criticado no curso dos anos setenta, ela já tinha sido questionada após a Primeira e a Segunda Guerras Mundiais. A partir deste momento, assistimos à uma verdadeira mutação: o quadro das preocupações muda e o cuidado com a edificação nacional diminui e finalmente desaparece. Situamo-nos no mundo contemporâneo, interrogamos os acontecimentos que têm uma ligação geracional com os professores e com os alunos. A perda do Império Colonial acentua o movimento nos anos 1960. As páginas negras da história nacional não parecem já ser tabus; a necessidade de transmitir uma memória se torna obsedante. Compreendemos que neste espaço condensado de fatos carregados de dores, a emoção muda de natureza e é mais significativa. Esta injunção social de um dever de memória, de um dever de transmitir, no curso dos anos oitenta e noventa, impregnou consideravelmente as práticas de sala de aula de temas tão delicados, de agora em diante, como a Segunda Guerra Mundial (até então tratada como história militar e diplomática) e as guerras de descolonização.

No fundo, se ousássemos fazer um atalho histórico dos séculos XIX e XX, o professor de história passaria da história santa do século XIX a uma história sagrada da nação e da pátria. Após o desencanto (LOUBES, 2001) do entreguerras, este ensino não seria instalado em uma história dessacralizadora, desconstrutiva da nação, em seguida à Segunda Guerra Mundial e à perda do Império, que encontra a sua forma acabada 
Por detrás destas questões carregadas de implicações de transmissão escolar está a questão da formação dos professores que está em jogo aqui. O relatório parlamentar enviado pelo Senhor Accoyer não diz outra coisa quando apela "com suas palavras a um reforço da formação permanente dos professores de história, e um suporte, se necessário, de maneira a aproximar a história ensinada na escola às evoluções recentes da pesquisa histórica." (ACCOYER, 2008, p. 183) Apoiados em conteúdos confiáveis, livres dos desafios de memória ou das temáticas trazidas por lóbis memoriais multiformes, os professores de história aos quais conviria acrescentar os Professores das escolas e os professores de outras disciplinas que o desejam, podem então abordar as páginas sóbrias da escola nacional. Ao mesmo tempo em que as inserem em um contexto histórico e lhes restituem a sua importância histórica. É a este preço talvez que uma consciência nacional apaziguada e sobretudo acautelada poderá restituir o conjunto da história nacional em toda a sua inteligibilidade a fim de esclarecer plenamente as implicações contemporâneas. Como diz a apresentação da obra de Jocelyn Latourneau, professor de história no Quebec, especialista dos desafios de memória, “é dever de cada geração despregar as cortinas, desempoeirá-las para que o cômodo respire ou para que entre uma nova luz" (LÉTOURNEAU, 2000).

“Nós vivemos à mercê de más lembranças." (MODIANO, 2007). Esta frase do romancista Patrick Modiano descreve a situação da Franca nesses últimos trinta anos, antes que a história da deportação dos judeus da Franca e o papel de Vichy na colaboração retornassem à memória de uma França dos anos 70-80 em plena crise econômica e social, abalada nas suas mais bem arrimadas certezas nos valores da República e dos direitos do homem. Neste contexto de hipermnésia, os professores, nas suas aulas, talvez já não tenham outra escolha senão aceitar o confronto com o ensino dos "temas recalcados" da história nacional, ou pelo menos da sua parte "controversa", rica de redefinição da identidade nacional. Contudo, Nicole Tutiaux Guillon e a maior parte dos trabalhos sobre o ensino mostram, por tradição, que o ensino da história repousa sobre a neutralização dos saberes e das suas implicações. Em todos os tempos, 
desde o papel desempenhado no currículo por Henrique IV, no momento da separação da Igreja do Estado, a escola e o seu currículo conheceram os seus efeitos de "resfriamento" das questões delicadas. Françoise Lantheaume mostrou nos seus trabalhos como a dimensão moral mobilizada para falar da guerra e das vítimas permitia transferir para os direitos do homem a questão da violência da descolonização durante a guerra da Argélia. Portanto, e se seguirmos Paul Ricoeur, que falava de uma necessidade de "justa memória", talvez seja permitido e urgente chamar a uma "justa pedagogia" da história, que possa construir uma história crítica sem subestimar a força social da memória em jogo, que possa ser fiel ao passado sem renegar a verdade e ser fiel à verdade acadêmica, sem retirar nada da dignidade das pessoas inseridas na história.

\section{Referências}

ABECASSIS, Frédéric. et al. La France et l'Algérie, leçons d'histoire, sous direction de, coll. " éducation, histoire, mémoire », INRP, 2007.

ACCOYER, Bernard. (Org.) Rapport d'information sur les questions mémorielles, Assemblée nationale, $n^{\circ} 162,18$ novembre 2008

ANDERSON, Benedict. L'imaginaire national. Réflexions sur l'origine et l'essor du nationalisme. Paris: La Découverte, 2002.

BALLINI, Pier Luigi; PÉCOUT, Gilles, (Org.) Scuola e nazione in Italia e in Francia nell'Ottocento.Venise: Instituto venete di scienze, lettere ed arti, 2007

BEN AMOS, Avner. Israël : la fabrique de l'identité nationale.Paris: CNRS éditions, 2010

BENAYOUN, A. M.; BOYER, Gilles, FALAIZE, Benoît. La place de la colonisation dans les manuels scolaires de l'école primaire. Rapport INRP, novembre 2007

BONAFOUX, Corinne; DE COCK, Laurence, FALAIZE, Benoit. Mémoires et histoire à l'école de la République, « débats d'école », Armand Colin, 2007

BORNE, Dominique. Faire connaître la Shoah à l'école. Les cahiers de la Shoah, n.1, Liana Levi 1994 
BRANCHE, Raphaëlle. La torture et l'armée pendant la guerre d'Algérie, 1954-1962, Gallimard, 2001

BRUTER, Annie. L'histoire enseignée au Grand Siècle. Naissance d'une pédagogie.Paris:Belin, 1997

CABANEL, Patrick.Le tour de la nation par des enfants: romans scolaires et espaces nationaux (XIX ${ }^{e}-X^{e}$ siècles)., Paris: Belin. 2007. (coll. Histoire de l'éducation)CITRON, Suzanne,Le Mythe national: Local: Editions ouvrières, 1989

COMITÉ POUR LA MÉMOIRE DE L'ESCLAVAGE. Mémoires de la traite négrière de l'esclavage et de leurs abolitions., . Local: La Découverte, 2005. (Préface de Maryse Condé: "Sur le vif»)

CONAN, Éric; ROUSSO, HenryVichy, un passé qui ne passe pás. Paris: Gallimard, 1996. (Coll. Folio-Histoire)CORBEL, Laurence; FALAIZE, Benoît. Entre mémoire et savoir : l'enseignement de la Shoah et des guerres de décolonisation, IUFM de l'Académie de Versailles/INRP, 2003

DETIENNE, Marcel.L’identité nationale, une énigme.Paris: Gallimard, 2010. (Coll. FolioHistoire)

DEVELAY, Michel. De l'apprentissage à l'enseignement : pour une épistémologie scolaire. Local: ESF, 1995

DEYENOVA, Lililana. Les manuels après la bataille : les livres d'histoire nationale en Bulgarie après 1944 et après 1989 ", Histoire de l'éducation, Paris: INRP, , n.86, 2000, p. 171176, EIZLINI, Carine, La colonisation enseignée aux enfants de Jules Ferry à nos jours, cas des manuels d'histoire du cours élémentaire et moyen, Mémoire de Master 2 recherche sous la direction de Claude Lelièvre (Paris 5), 2005

FALAIZE, Benoît, HEIMBERG, Charles, LOUBES, Olivier, (Org.)L'école et la nation.Lyon:ENS éditions, 2013.

FALAIZE, Benoît (Org.); ABSALON, Olivier; MÉRIAUX, Pascal.L'enseignement de l'histoire de l'immigration à l'école, Rapport de recherche, INRP, octobre 2007

FALAIZE, Benoît, (Org.)Enseigner l'histoire de l'immigration à l'école, coll. « éducation, histoire, mémoire ", INRP/CNHI, 2008

FALAIZE, Benoît (Org.)L'enseignement de l'esclavage et de la traite négrière dans l'espace scolaire hexagonal, INRP, 2009 ; http://ecehg.ens-lyon.fr 
GRIGNON, Max.Livre d'histoire: fin d'études primaires. Local: Editora, 1950

HOBSBAWM, Eric; RANGER, Terence (Org.) L'invention de la tradition.Paris: Édition Amsterdam, 2006

LANTHEAUME, Françoise.L'enseignement de l'histoire de la colonisation et de la décolonisation de l'Algérie depuis les années trente: Etat-nation, identité nationale, critique et valeurs. Essai de sociologie du curriculum. (tese) - Ecole des Hautes Etudes en Sciences Sociales, Doctorat de sociologie, Paris, tapuscrit, 2002

LANTHEAUME, Françoise.Enseigner l'histoire de la guerre d'Algérie : entre critique et relativisme, une mission impossible ?, in LIAUZU, C. (Org.). Tensions méditerranéennes.Paris:Cahiers Confluences Méditerranée-L'Harmattan, 2003, p. 231-265

LECOMTE, Jean-Michel; GIACOMETTI, Nicolas.Enseigner sur la Shoah. Local:, Centre régional de documentation pédagogique de Bourgogne, 1998

LEGARDEZ, Alain SIMONNEAUX, Laurence. L'école à l'épreuve de l'actualité: enseigner les questions vives. Local: ESF, 2006

LÉTOURNEAU, Jocelyn. Passer à l'avenir. Boréal, Montréal, Québec: Editor, 2000

LOUBES, Olivier.L'école et la patrie:histoire d'un désenchantement, 1914-1940. Belin: 2001.

MAYORGA, Rodrigo (Org.)Escribir a Chili desde la escuela: conciencia historica e investigacion escolar entre centenarios (1910-2010). Santiago: RIL editores, 2011

MÉRIAUX, Pascal; FALAIZE, Benoît. Le génocide arménien à l'école. Local: INRP, 2006

MILZA, Pierre; BERSTEIN, Serge.Histoire, classe de $4^{\text {ème }}$. Local: Nathan, 1970

MODIANO, Patrick. Dans le café de la jeunesse perdue. Local: Gallimard, 2007

POUSSE, Carine(Org.) La place de l'esclavage et de la traite négrière dans les manuels scolaires, Rapport INRP, novembre 2007 
SCHNUR, Emma; ERNST, Sophie.Pédagogiser la Shoah ?. Le Débat, n.96, p.00-00, septembre-octobre 1997

THÉNAULT, Sylvie.Une drôle de justice: les magistrats dans la guerre d'Algérie. Local: La découverte, 2001

TUTIAUX-GUILLON, Nicole; NOURISSON, Didier, (Org.) Identités, mémoires, conscience historique. Local: Publications de l'Université de Saint-Etienne, 2003 